\title{
Ora - Save the Forest! Designing a Social Impact Game
}

\author{
Hazel Bradshaw ${ }^{1}$, E. Penelope Holland ${ }^{2}$, and Mark Billinghurst ${ }^{1}$ \\ ${ }^{1}$ The Human Interface Technology Laboratory, Christchurch, New Zealand \\ Hazel.Bradshawecanterbury.ac.nz, \\ mark.billinghurst@hitlabnz.org \\ ${ }^{2}$ Landcare Research, Lincoln, New Zealand \\ HollandP@landcareresearch.co.nz
}

\begin{abstract}
Computer models for designing educational games need to have practical applications as well as underlying theoretical principles. In this paper, we present the Structural Playability Process (SPP), a new approach for designing and implementing serious games. Using the SPP designed game Ora - Save the Forest! as a case study, we describe the four SPP spaces: education, translation, design and engine. Ora is a forest-pest-management game based on scientific models and intended to inform players about the complexities of ecosystem management. Preliminary user study results show that SPP is an effective method of producing motivating and successful learning environments.
\end{abstract}

Keywords: Serious/Educational games, Game-design, Structural Playability (SPP), Flow, Motivation, Game-play.

\section{Introduction}

Computer games stimulate motivation, skill development and affect learning and knowledge acquisition [1,2]. There is a need for more empirical evidence supporting the effectiveness of games as learning environments [3], but game design is key in finding a balance between education and games [4]. Game design models bring structure to the design of educational games by applying motivation theories, among which Csikszentmihalyi's [5] Flow theory is prominent. Design models utilising Flow for educational game design $[6,7,8]$ provide insight into how to align theory with game design, but rarely cover the practical implementation of a game.

This paper describes the design approach for "Ora - Save the Forest!"” A social impact game designed using the novel Structural Playability Process (SPP) to meet the need for a practical methodology for educational game design. The SPP draws on several theories in psychology: skilled performance theory [9]; motivational theories $[10,11]$ and optimal experience or 'Flow' [5]. Flow is an eight stage state of optimal experience, where the 'experiencer' is intrinsically motivated to continue engaging with the task at hand.

${ }^{1}$ http: / / www playora.net/

Y. Pisan et al. (Eds.): ICEC 2014, LNCS 8770, pp. 84-91, 2014.

(C) IFIP International Federation for Information Processing 2014 
Theoretically, development of computer games which create conditions for 'Flow' [12] can produce 'intrinsic motivation' [11], inspiring the player to take on further challenges and drive their learning experience. Our research explores the connection between game design, Flow and learning gains. In the rest of the paper we first describe the Ora - Save the Forest! Game, focusing on the SPP methodology, then results from a user study conducted with the game, and finally conclusions and directions for future work.

\section{Ora - Save the Forest!}

At the heart of the SPP is the application of skilled performance theory, which structures the design of game mechanics to provide a scaffold upon which the experience of Flow can be developed. The four design and development spaces of the SPP are 1) Education, 2) Translation, 3) Design and 4) Engine. The primary advantage of this approach, over others, is that the gameplay process breaks down into spaces that can be engaged with by all stakeholders, from client to designer to programmer. The SPP spaces link learning outcomes to gameplay mechanics and offer a practical implementation method for structuring gameplay inside a game engine. In the rest of this section we describe how the SPP was applied in the design and development of "Ora Save the Forest!".

2.1 The Educational Space (1) of the SPP drives game design by linking a complex problem to a narrative via learning outcomes. The designer works closely with the client to explore and contextualise the game concept. This requires defining a target audience, and their intrinsic and extrinsic motivations [5][11]. Understanding client and audience motivations helps establish the learning outcomes, learning objectives and objective tasks.

A Complex Problem - Pest control in New Zealand is a contentious issue: research indicating the consequences of management is not well understood by some members of the general public who have a stake in the process (e.g. land owners and managers, recreational land users). The public need to be engaged in order to make informed decisions about pest management on their land or communities. Academic papers are difficult to access for the layperson, and most scientific knowledge transfer to date has been via media releases, workshops or word of mouth. It is difficult to get a national scale audience engaged via these routes. Developing a game based on pest management research is a novel way to engage and inform the public with up to date science, and to help players gain a realistic appreciation that ecosystem management is a complex problem (the primary learning outcome).

Client and Target Audience - The client was Landcare Research, a NZ Crown Research Institute involved in terrestrial biodiversity management. The target audience was the NZ public with a core demographic of rural New Zealanders of both genders, with a tertiary education but not necessarily academics.

Defining motivations - Key outcomes for the game were; to provide an aid to public dialogue and engagement with a complex problem, scientific knowledge transfer, and innovative and engaging ways to implement and present research findings. 
Intrinsic motivations come from the inside; for example, wanting to achieve the aspirational goal of maintaining and restoring New Zealand's forest ecosystem and biodiversity. This intrinsic motivation is shared between client and target audience, and became the learning objective for Ora. Extrinsic motivations come from the outside; for example, wanting to see the results of the learning objective. The client-centred extrinsic motivations were to control possum population dynamics temporally and spatially, with the aim of promoting understanding and awareness of the effectiveness of available possum control options. The game should therefore allow players to interact with the underlying science to experience this. The extrinsic motivators of the target audience were to see native bird and tree recovery and maintain a $100 \% \mathrm{NZ}$ Pure perception. Therefore, the game-world, its narrative and rewards should display these results, following appropriate in-game actions.

Learning outcomes - Using learning outcomes for defining and assessing student performance is well established in higher education [13]. Learning outcomes and objectives ultimately define the primary game goals in the correct context. Considering the motivations of client and target audience allowed us to define the learning outcome and objectives for Ora: participants should be able to gain a realistic appreciation that management of an ecosystem is a complex problem. This learning outcome provided the educational design and directive for player achievement, and describes the scope of the activity for player and designer. The player's path to meet the learning outcome is via the application of learning objectives, broken down into objective tasks. Objective tasks guiding Ora gameplay design are to monitor the environment to assess tree health and possum impacts, and to manage the environment.

2.2 The Translation Space (2) is where learning objectives and objective tasks are embedded within a simple narrative, contextualising the gameplay for the player and the designer who aims to 'maximize the player experience through the planning, structure and execution of the key elements of Gameplay Progression (mechanics, duration, ancillary rewards, practical rewards and difficulty)' [14].

Narrative - Ora places the player at the heart of the action: You are the hero tasked with saving the beautiful but fragile native forest from the jaws of hungry invaders. The narrative was established to reflect client and target audience motivations. The setting is native NZ forest, invaded by Australian brushtail possums, the player is introduced to the game world by an omnipresent entity, the guardian of the forest, who enlists the player's help in returning the ecosystem to its former glory. A giant tree at the centre of the virtual forest is the physical embodiment of the forest guardian. This "control tree" houses the gameplay interface that the player uses to monitor, interact and control the underlying forest-pest-management models. It is here that we find the non-player character Liana, a scientist who acts as liaison between guardian, game-world and player. Liana provides the narrative context and acts as the gameplay mission delivery system, and is the player's main point of contact inside the game.

2.3 The Design Space (3) is where the educational content is mapped into gameplay. To meet the learning outcome, the learning objectives are translated into a set of primary game goals that guide gameplay development through skill stages. Skill stages are a core device of the SPP. They apply the skilled performance scaffold which 
elicits Flow conditions. In the SPP, there are three types of gameplay goals; Aspirational/long-term goals (intrinsic); Mid-range goals (intrinsic/extrinsic); and Shortterm immediate goals (extrinsic).

The primary game goals result from the translation of learning outcomes and objectives filtered through the narrative. They reflect player motivations and form the basis of the narrative progression. In Ora, the primary game goals are (1): To repel an army of mammalian pests led by marauding possums (immediate motivational goal and direct player action); (2): To save the native flora and fauna (mid-range goal and reinforcer of player action); (3): To restore the forest ecosystem to its former glory (success indicator and long-term aspirational goal creating opportunities for feedback on actions).

The simulation model ( $\mathrm{sim})$ that underlies Ora provides the player with methods for achieving gameplay goals. It integrates models of possum birth, death and movement [15], impacts on tree health and mortality [16] and interactions with management tools such as traps [17] and poison bait [18], with costs (time and money) for executing monitoring or management. The sim allows players to set up "operations" comprising a series of actions such as choosing contractors, transport and equipment, setting trap or bait station layout, providing quotes, and implementing operations at the appropriate time, thus providing a basis on which to build gameplay mechanics.

Gameplay - The design plan for Ora has four levels, which deal with the challenges of using the available tools within limited budgets, ethical dilemmas and meeting the needs of concerned citizens. These are: (Level 1) Ground operations; (Level 2) Aerial operations; (Level 3) Managing stakeholders; (Level 4) Combination of levels 1-3. In this paper we focus on the gameplay development of Level 1 which comprises a 61 hectare area of forest enclosed by a predator-proof fence. The forest consisted of three native, palatable tree species (Kamahi, Southern rata and Hall's Totara) and the initial possum population was set at 20 per hectare with an equal sex ratio. Interactions between trees and possums were controlled by the sim, which allows the trees to grow and change over time while showing the impacts of possum browse on the forest canopy. In-game possums move around the gameplay area, with movements dictated by the position of their home ranges. Game time is moved at roughly one night per second of play, so 15 minutes of gameplay could equate to 2.5 years of forest time. The game needed to make player perception of involvement close to that of the client and/or other entities involved in implementing or directing pest control in NZ. We therefore developed a system of reward and feedback that enables players from the public, scientists and managers to perceive the value of each other's input.

Epic win and fail - The outcome for Level 1 was to establish good tree health and a healthy bird population, by reducing possum numbers in the fenced area. The Level 1 'Epic Win' state would see possums eradiated inside the fenced area and trees at $80 \%+$ attainable health, and the release of a player-nurtured kiwi into the newly created sanctuary. The 'Epic Fail' state would be the opposite, with a healthy possum population, less than $20 \%$ tree health and an unhatched egg or unreleased kiwi. To achieve the level goal, the player must access ground-based pest control options in the sim: Tree Monitoring; Trapping; and Baiting. The in-game application of these operations form the goal orientated skill based tasks of level 1. 
Skill stages - To manage task progression, gameplay was subdivided into four skill stages, drawing on the 'Three Phases of Skill Learning' [19] and the principles of achieving a skilled performance [9]. A skill stage has five components: the challenge to be undertaken, tasks contributing to the challenge, feedback on tasks, rewards for task completion, and progression to the next skill stage. This logical structure guides the pacing of goal orientated progression, by building on levels of complexity and challenge. Ideally, this progression creates Flow [5], as challenge and skill increase simultaneously to balance player anxiety and boredom. Level 1 is a tutorial level, sitting in the Cognitive or Early phase of skill learning, 'Where a learner tries to understand the task and what is being demanded of them' [9]. The design allows the player to learn the game interface, control system and ground-based management options. Within Level 1, skill stages progress in complexity and size. Skill Stage 1 starts with basic tree monitoring in 1 hectare of playable space, increasing to the complete tool box of ground control strategies across 61 hectares by Skill Stage 4 (Fig. 1).

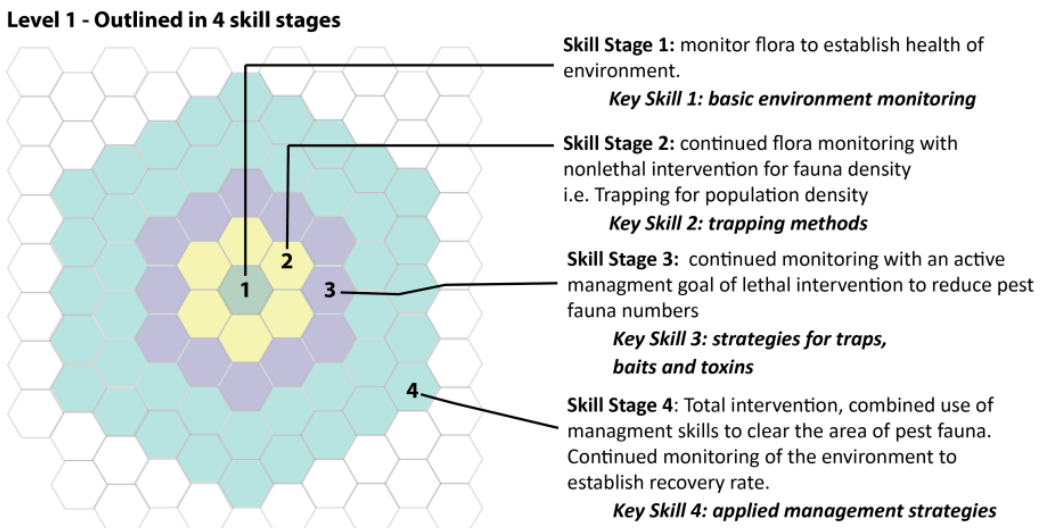

Fig. 1. Map of skill stage tasks increasing in difficulty and spatial complexity

The User Interface (UI) - Supporting and contextual gameplay features were developed within the skill stages, using the narrative to tie them together. The UI was designed to deliver a cohesive user experience throughout the skill stages. From the control tree (see Translation Space), the player accesses game controls, sets out to explore a 3D forest environment, interacts with the feedback and reward system, and meets Liana, who guides the player through the gameplay missions (see Engine).

Rewards and Feedback - Feedback on individual tasks is delivered via the Logbook, giving feedback from the sim (e.g. tree health after a monitoring operation, number of possums trapped after a trapping operation), allowing players to interact directly with the underlying science. Indirect feedback is provided by updating the forest health status, which is tracked by in-game status graphs, and by visually updating the displayed trees to show possum browse and canopy recovery. The game also features a native birdlife nurture system. During level 1, the player is awarded a kiwi egg, which they must attempt to hatch and release into the sanctuary. Successful management intervention to complete a gameplay mission gives the player science points, 
which increase the hatching rate of the egg. This reward system focuses the player on the positive aspects of pest management (e.g. saving birds) rather than the negative (e.g. killing possums), and gives the player a simple scale of achievement to follow (e.g. get enough science points to hatch the bird).

2.4 The Engine Space (4) is where the game design is implemented in software. The Design space skill-stages become the gameplay missions that are coded in the engine mission system. Off-the-shelf game engines, such as Unity3D in this project, do not have built-in mission systems for implementing gameplay. The SPP, unlike more theoretical design processes $[6,7,8]$ provides a practical means for creating a logic based, engine-side mission system, comprising of four, hierarchical steps: 1) Mission Control; 2) Mission Set; 3) Missions; 4) Mission Objective.

1. Mission Control has controls for setting gameplay parameters for the entire gameplay level (Fig 2, left). Mission Control initiates the sim and mission sets, checks for completion, then iterates a new set or ends gameplay. Nested within Mission Control is the:

2. Mission Set, which holds all related missions defined under the relevant skill stage. This follows the same pattern as Mission Control, checking and instantiating all missions linked to the Mission Set as needed. The Mission Set contains:

3. Missions. The Mission starts by triggering the onscreen mission delivery system (Fig 2. centre, Liana dialogue) and deeper levels of player guidance (by producing Journal entries). When the player completes their interaction with Liana, a:

4. Mission Objective is triggered. The Mission Objective houses gameplay tasks the player will undertake. On completion of the Mission Objective, the logic either starts the next objective in sequence or begins the mission completion sequence. The completion logic provides feedback dialogue to the player from Liana on the outcomes of the mission. It then triggers the reward and any other feedback systems that are linked to that particular mission (Fig 2. centre). The Mission is then flagged as complete and triggers the next Mission in the Set, or gameplay ends.

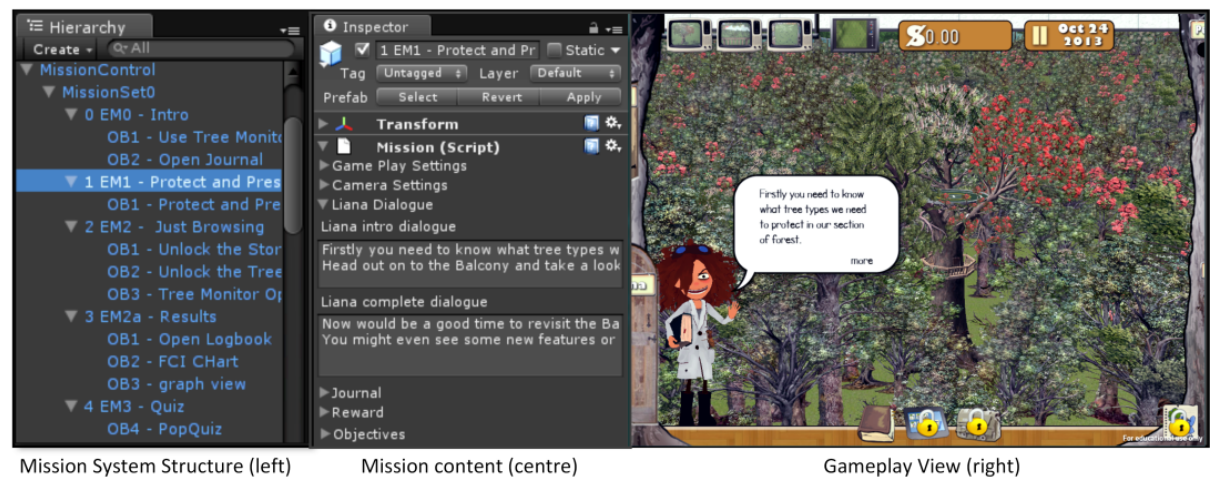

Fig. 2. SPP Engine Space mission system applied in (Unity3D) game engine 


\section{$3 \quad$ Results}

The game design was tested using: (1) pre/post and follow-up tests measuring knowledge acquisition and (2) the EGameFlow [20] survey of participant enjoyment on Flow. We compared the Ora game (ORA) to a classroom experience of the sim (SIM), which shared the UI and 3D world environment of Ora, but did not include skill stage mapping and mission delivery (Liana). The hypotheses stated: (a) the SPPdesigned ORA would provide a learning environment that better supported knowledge acquisition in SIM; and (b) ORA would better promote 'Flow' state conditions.

Participants were recruited (26 female and 26 male, 18-50 age range) from Canterbury, NZ. Survey answers for knowledge acquisition and Flow were summarized for each player to give a score per survey (pre/post/follow-up). We found that players of the SIM learned slightly more immediately after the user study (post) compared to before (pre), with the average degree of change between pre and post surveys equal to $22 \%$ for ORA and $27 \%$ for SIM.

However, knowledge retention after 4 weeks was higher for ORA than SIM: no significant change $(\mathrm{p}=1.0)$ could be detected in the follow-up survey from pre-test levels for SIM players, but ORA players retained a significant amount of knowledge $(\mathrm{p}<.003)$ compared to pre-test levels. ORA players also had a more positive perception of the experience than SIM players: overall 56\% of ORA players responded positively to experiencing Flow conditions compared to only 33\% for SIM players. There was also a statistically significant difference between the two groups in the Flow conditions of Feedback (Mann-Whitney $\mathrm{U}=151, \mathrm{p}<.001$ ) and Immersion (MWU = $231.5, \mathrm{p}<.05)$, with the mean rank significantly higher for ORA in both instances. Overall this confirms our hypotheses that the Ora game better supported long-term knowledge acquisition when compared to the classroom taught SIM, and that ORA also better promoted conditions of a 'Flow' state.

\section{Conclusion}

The four spaces of the SPP (Education, Translation, Design and Engine) provide a practical way to translate a client 'problem' into an effective gameplay environment. The use of motivation theories [5][11] to define learning outcomes, objectives and tasks provides a framework for structuring narrative and gameplay goals. Use of skill performance theory [9] based skill stages [19] link the Design and Engine spaces. This provides structure for Mission Sets with their system of challenges, tasks, feedback and reward into effective gameplay that improves the occurrence of a Flow state.

Implementing the Mission Set structure into a game engine provides a system supporting player progression and gameplay goal achievement. The fact that Ora gameplay resulted in greater knowledge retention, induced a more positive perception of Flow showing significantly better Feedback and Immersion when compared to the sim, suggests the SPP has the potential to be a powerful tool for educational game design. The Design and Engine Spaces are practical, straightforward, and general enough to be applied to any serious game concept. However, considerable collaboration is required by designer and client to work through the Education and Translation Spaces. For a game designer not experienced in teaching methods, mapping learning outcomes could prove 
challenging. Future opportunities for further dissemination and testing would come through collaboration with other game designers and projects.

\section{References}

1. Dondlinger, M.J.: Educational Video Game Design: A Review of the Literature. Appl. Educ. Technol. 4(1), 21-31 (2007)

2. Connolly, T.M., et al.: A systematic literature review of empirical evidence on computer games and serious games. Comput. Educ. 59(2), 661-686 (2012)

3. O'Neil, H.F., Wainess, R., Baker, E.L.: Classification of learning outcomes: Evidence from the computer games literature. Curric. J. 16(4), 455-474 (2005)

4. Wei, T., Li, Y.: Design of Educational Game: A Literature Review. In: Pan, Z., Cheok, A.D., Müller, W., Zhang, X., Wong, K. (eds.) Transactions on Edutainment IV. LNCS, vol. 6250, pp. 266-276. Springer, Heidelberg (2010)

5. Csikszentmihalyi, M.: FLOW: The Psychology of Optimal Experience. Harper \& Row (1990)

6. Kiili, K.: Towards a participatory multimedia learning model. Educ. Inf. Technol. 11, 2132 (2006)

7. Finneran, C., et al.: A person-artefact-task (PAT) model of flow antecedents in computermediated environments. Int. J. Hum. Comput. Stud. 59(4), 475-496 (2003)

8. Cowley, B., Charles, D., Black, M., Hickey, R.: User-System-Experience Model for User Centered Design in Computer Games. In: Wade, V.P., Ashman, H., Smyth, B. (eds.) AH 2006. LNCS, vol. 4018, pp. 419-424. Springer, Heidelberg (2006)

9. Fitts, P.M., Posner, M.I.: Human Performance. In: Human Performance. Brooks/Cole Pub. Co., Belmont (1967)

10. Maslow, A.H.: A theory of human motivation. Psychol. Rev. 50(4), 370-396 (1943)

11. Deci, E., Ryan, R.: Intrinsic Motivation and Self-Determination in Human Behavior, pp. 1-5, 28-40. Plenum Press, New York (1985)

12. Oblinger, D.: Simulations, Games, and Learning. Educause 39, 6 (2006)

13. Biggs, J.: Formulating and clarifying curriculum objectives. In: Teaching for Quality Learning at University, 2nd edn., pp. 34-55. Open University Press, Buckingham (2003)

14. Lopez, B.M.: Gameplay Design Fundamentals: Gameplay Progression. Gamasutra (2014), http: / / ubm. io/1maLykE (accessed: March 28, 2014)

15. Ramsey, D.S.L., Efford, M.G.: Management of bovine tuberculosis in brushtail possums in New Zealand: Predictions from a spatially explicit, individual-based model. J. Appl. Ecol. 47(4), 911-919 (2010)

16. Holland, E.P., et al.: Thresholds in plant-herbivore interactions: Predicting plant mortality due to herbivore browse damage. Oecologia 172(3), 751-766 (2013)

17. Ball, S.J., et al.: A method for estimating wildlife detection probabilities in relation to home-range use: insights from a field study on the common brushtail possum (Trichosurus vulpecula). Wildl. Res. 32(3), 217 (2005)

18. Tompkins, D.M., Ramsey, D.: Optimising bait-station delivery of fertility control agents to brushtail possum populations. Wildl. Res. 34(1), 67 (2007)

19. Bradshaw, H.: Entertainment Education For The Computer Age: Investigating The Engaging Nature of Computer Games for Educational Application. In: ICERI 2010 Conference, pp. 3772-3781 (November 2010)

20. Fu, F.-L., Su, R.-C., Yu, S.-C.: EGameFlow: A scale to measure learners' enjoyment of elearning games. Comput. Educ. 52(1), 101-112 (2009) 